\title{
Neurotoxic Catecholamine Metabolite in Nociceptors Contributes to Painful Peripheral Neuropathy
}

\author{
Olayinka A. Dina ${ }^{b, e}$, Sachia G. Khasar ${ }^{b, e}$, Nicole Alessandri-Haber ${ }^{b, e}$, Oliver Bogen $^{b, e}$, \\ Xiaojie Chen $^{\mathrm{b}, \mathrm{e}}$, Paul G. Green ${ }^{\mathrm{b}, \mathrm{e}}$, David B. Reichling ${ }^{\mathrm{b}, \mathrm{e}}$, Robert O. Messing ${ }^{\mathrm{c}, \mathrm{d}, \mathrm{f}}$, and Jon D. \\ Levine ${ }^{a, b, d, e}$ \\ aDepartment of Medicine, University of California at San Francisco, CA 94143-0440, USA \\ bepartment of Oral \& Maxillofacial Surgery, University of California at San Francisco, CA \\ 94143-0440, USA \\ 'Department of Neurology, University of California at San Francisco, CA 94143-0440, USA \\ ${ }^{\mathrm{d} D i v i s i o n}$ of Neuroscience and Biomedical Sciences, University of California at San Francisco, CA \\ 94143-0440, USA \\ eUCSF NIH Pain Center, University of California at San Francisco, CA 94143-0440, USA \\ fErnest Gallo Clinic and Research Center, Emeryville, CA 94608
}

\begin{abstract}
Neurotoxic effects of catecholamine metabolites have been implicated in neurodegenerative diseases. Since some sensory neurons express tyrosine hydroxylase and monoamine oxidase (MAO) we investigated the potential contribution of catecholamine metabolites to neuropathic pain in a model of alcoholic neuropathy. The presence of catecholamines in sensory neurons is supported by capsaicin-stimulated epinephrine release, an effect enhanced in ethanol-fed rats. mRNA for enzymes in dorsal root ganglia involved in catecholamine uptake and metabolism, dopamine $\beta$-hydroxylase and MAO-A, were decreased by neonatal administration of capsaicin. Ethanol-induced hyperalgesia was attenuated by systemic and local peripheral administration of inhibitors of MAO-A, reduction of norepinephrine transporter (NET) in sensory neurons, and a NET inhibitor. Finally, intradermal injection of 3,4-dihydroxyphenylglycolaldehyde (DOPEGAL), a neurotoxic MAO-A catecholamine metabolite, produced robust mechanical hyperalgesia. These observations suggest that catecholamines in nociceptors are metabolized to neurotoxic products by MAO-A, which can cause neuronal dysfunction underlying neuropathic pain.
\end{abstract}

\section{Keywords}

catecholaminergic neurons; DOPEGAL; epinephrine; norepinephrine; mitochondria; rat

\section{Introduction}

One aspect of the pathophysiology of neurodegenerative diseases like Parkinson's and Alzheimer's disease is the death of catecholaminergic neurons in the brain (Burke et al., 2004; Rommelfanger \& Weinshenker, 2007). Evidence suggests that this cell death is caused, at least in part, by the generation of highly reactive aldehyde metabolites of

Address correspondence to: Jon D. Levine, M.D., Ph.D., Box 0440, C-522, University of California, San Francisco, San Francisco, CA 94143-0440. Phone \#: (415) 476-5108. Fax \#: (415) 476-6305. Jon.Levine@ ucsf.edu. 
catecholamines inside those cells, due to the action of monoamine oxidase (MAO) (Burke et al., 2004). In particular, 3,4-dihydroxyphenylglycolaldehyde (DOPEGAL), a MAO-A metabolite of catecholamines is neurotoxic to CNS neurons (Burke et al., 2004).

Catecholaminergic neurons may be particularly vulnerable because they not only synthesize and metabolize catecholamines, but they also possess active transport mechanisms for reuptake, allowing them to accumulate catecholamines from the extracellular space (Burke et al., 1999; Keller et al., 2004; Rusnak \& Gainer, 2005). Fig. 1 summarizes the catecholamine metabolic pathway (Flatmark, 2000; Eisenhofer et al., 2004).

Peripheral neuropathies are also associated with dysfunction, damage, and sometimes the death of neurons, often due to neurotoxic effects on subpopulations of neurons (Creange, 2004; Hoitsma et al., 2004; Freeman, 2005; Jamieson et al., 2005; Freeman, 2007). We hypothesized that a neurotoxic catecholamine metabolite also contributes to peripheral neuropathy, because some somatosensory neurons exhibit markers of a catecholaminergic phenotype. For example, up to $15 \%$ of sensory neurons in the adult rodent express tyrosine hydroxylase, the rate-limiting enzyme for catecholamine synthesis (Katz et al., 1983; Price \& Mudge, 1983; Price, 1985; Katz \& Black, 1986; Katz et al., 1987; Vega et al., 1991; Brumovsky et al., 2006), and some express MAO (Vega et al., 1991).

Alcohol-induced painful small-fiber peripheral neuropathy can cause severe pain that has been described as "like tearing flesh off the body" (Brain \& Walton, 1969). In this peripheral neuropathy, primary afferent nociceptors become dysfunctional (Dina et al., 2000; Chen \& Levine, 2007) and may ultimately degenerate (Koike et al., 2001). Although neurotoxicity is assumed to be an important factor, the underlying mechanisms responsible for the painful neuronal dysfunction remain poorly understood. Since chronic alcohol consumption is associated with high plasma levels of catecholamines (Patterson-Buckendahl et al., 2005), we tested the hypothesis that neurotoxic effects of catecholamine metabolites contribute to enhanced nociception in alcoholic neuropathy. Importantly, we have already established that our model of alcohol-induced painful neuropathy is highly sympathoadrenal-dependent (Dina et al., 2008).

\section{Materials and Methods}

\section{Animals}

Male (220-450 g) Sprague-Dawley rats (Charles River, Hollister, CA, USA) were housed in the Laboratory Animal Resource Center of the University of California, San Francisco under a 12-hour light/dark cycle. The experimental protocols were approved by the University of California, San Francisco Institutional Animal Care and Use Committee and conformed to $\mathrm{NIH}$ guidelines for care and use of experimental animals.

\section{Drugs}

The drugs used in these experiments were: clorgyline hydrochloride, desipramine hydrochloride, (-)-epinephrine bitartrate, pargyline hydrochloride (Sigma, St. Louis, MO), capsaicin (Tocris, Ballwin, MO) and 3,4-dihydroxyphenylglycolaldehyde (DOPEGAL, synthesized by Dr. Shu Wen Li, Beaverton, OR). Desipramine was dissolved in distilled water. Epinephrine was dissolved in $0.9 \%$ saline containing $1 \mathrm{mg} / \mathrm{ml}$ ascorbic acid and loaded in Alzet osmotic pumps. All other drugs were dissolved and diluted in normal saline.

\section{Ethanol administration}

The rats, housed 1 per cage, were divided into 2 main groups: ethanol and control diet. The ethanol-diet rats were fed a Lieber-DeCarli liquid diet (Dyets Inc., Bethlehem, PA) containing ethanol (6.5\% v/v) (Lieber \& DeCarli, 1989a; Lieber et al., 1989; Dina et al., 
2000; Dina et al., 2006). Control-diet rats were pair-fed (i.e. calorie-matched to the ethanolfed rats) with a diet that contains maltose-dextrin in place of ethanol (Lieber \& DeCarli, 1989b). The protocol for ethanol administration was 4 days of free access to ethanol followed by 3 days of ethanol-free control diet ( $4 \mathrm{~d}$ on/3d off (Dina et al., 2006)). In this protocol, ethanol-induced hyperalgesia is detectable by the end of the first week, is maximal by 3 weeks and is exacerbated by withdrawal (Dina et al., 2006).

\section{Nociceptive behavior}

The mechanical nociceptive threshold was quantified using the Randall-Selitto paw pressure test (Randall \& Selitto, 1957), in which a force that increases linearly over time (Algsymeter ${ }^{\circledR}$, Stoelting, Chicago, IL, USA), is applied to the dorsum of the rat's hind paw. This protocol has been used extensively in alcohol-naive (Taiwo et al., 1989; Dina et al., 2001; Dina et al., 2004; Hucho et al., 2006), alcohol-fed (Dina et al., 2000) and alcohol withdrawing (Dina et al., 2006) rats. Rats were lightly restrained in cylindrical transparent acrylic restrainers designed to provide adequate comfort and ventilation, and minimize restraint stress. All rats were acclimated to the testing procedure such that restraint and test techniques were performed in parallel across groups. Briefly, rats were placed individually in restrainers for $1 \mathrm{hr}$ prior to starting each study and for 30 min prior to testing on each test day (Dina et al., 2006). Nociceptive threshold was defined as the force (in grams) at which the rat withdrew its paw. The baseline paw-withdrawal threshold was defined as the mean of 3 readings before ethanol or control liquid diet was started. Each paw was treated as an independent measure and each experiment was performed on a separate group of rats. Each experimental group was tested weekly in order to determine the change in nociceptive threshold in response to the ethanol or control diet. All behavioral testing was done between $10 \mathrm{AM}$ and $4 \mathrm{PM}$.

\section{Adrenal medullectomy and lumbar sympathectomy}

To eliminate catecholamines derived from the adrenal medulla and postganglionic sympathetic nerves, both the adrenal medulla and lumbar sympathetic chains were surgically excised from rats, referred to as "double-surgery" rats. Both surgical procedures were performed under isoflurane anesthesia $\left(2.5 \%\right.$ isoflurane in $\left.\mathrm{O}_{2}\right)$. The adrenal glands were located through a lateral incision in the abdominal wall, their capsules cut open and the adrenal medulla excised, bilaterally (Wilkinson et al., 1981; Khasar et al., 1998). Rats were given $0.45 \%$ saline to drink, in place of water, for the first 7 days after adrenal medullectomy. Seven days after adrenal medullectomy, sympathetic denervation of the hind limbs was carried out, as previously described (Miao et al., 1995; Khasar et al., 2002). Briefly, the lumbar sympathetic chains, from $L_{2}$ to $L_{5}$ ganglia, were surgically removed bilaterally, via a lateral extraperitoneal approach. This surgery removes the sympathetic innervation of the hind limb (Baron et al., 1988). "Double-surgery" rats were fed ethanol or control diet starting 7 days after sympathectomy, and were used for experiments after being fed ethanol or control diet for 3 weeks.

\section{Tyrosine hydroxylase immunohistochemistry}

Confirmation of the efficacy of the sympathectomy was obtained by tyrosine hydroxylase immunohistochemistry. Rats were deeply anaesthetized with sodium pentobarbital (100 mg/ $\mathrm{kg}$, i.p. ) and transcardially perfused with $30 \mathrm{ml}$ heparinized PBS $(100 \mathrm{U} / \mathrm{ml})$ followed by $400 \mathrm{ml}$ PBS containing $4 \%$ paraformaldehyde, $\mathrm{pH} 7.3$. $\mathrm{L}_{5}$ dorsal root ganglia were immediately excised and post fixed for $2 \mathrm{~h}$ in the perfusion fixative. The ganglia were sequentially stored in PBS containing 10, 20 and $30 \%$ sucrose at $4^{\circ} \mathrm{C}$ for 12 to $24 \mathrm{hr}$, and then embedded in Tissue Tek O.C.T compound (Electron Microscopy Sciences, Hatfield, PA) sectioned at $20 \mu \mathrm{m}$ and thaw-mounted on slides. 
For immunohistochemistry, tissue sections were incubated for 30-min in PBS containing $0.3 \% \mathrm{H}_{2} \mathrm{O}_{2}$, at room temperature, to quench endogenous peroxidase activity. After 3 rinses in PBS, tissue sections were permeabilized and blocked for $1 \mathrm{hr}$ at room-temperature with "antibody dilution buffer": PBS containing 0.3\% Triton X-100 and 10\% normal goat serum (Jackson Immunoresearch Laboratories, West Grove, PA), and then incubated in 1:1500 rabbit anti-tyrosine hydroxylase antibody (AB 152, Chemicon, Temecula, CA) in antibody dilution buffer at $4{ }^{\circ} \mathrm{C}$ overnight. After 3 washes in PBS containing $0.3 \%$ Triton X-100 ("washing buffer") for $10 \mathrm{~min}$ each, sections were incubated for $2 \mathrm{hr}$ at room temperature with a 1:400 dilution of a biotinylated goat anti-rabbit antibody (Jackson Immunoresearch) in antibody dilution buffer, and washed 3 times in PBS. They were then incubated for $1 \mathrm{hr}$ at room temperature in 1:400 ABC Elite solution (Vector Laboratories, Burlingame, $\mathrm{CA}$ ) in antibody dilution buffer, and washed 3 times in PBS. Sections were then incubated in 1:1000 biotinylated tyramine in PBS containing 0.3\% Triton X-100 and $0.006 \% \mathrm{H}_{2} \mathrm{O}_{2}$ for 6 $\mathrm{min}$ at room temperature; biotinylated tyramine was prepared as described elsewhere (Kerstens et al., 1995). After 3 rinses with washing buffer, anti-tyrosine hydroxylase immunoreactivity was revealed by $1 \mathrm{hr}$ incubation at room temperature in 1:500 streptavidin-conjugated fluorescein (Jackson Immunoresearch). Sections were washed 3 times in PBS for 10 min each, and mounted on slides with Fluoromount G (Southern Biotechnology, Birmingham, AL).

Confocal images were captured using a confocal microscope (Zeiss, Thornwood, NY). The only digital manipulation performed was to match the brightness and contrast of the images.

\section{RT-PCR in dorsal root ganglia}

To determine if mRNA for $\mathrm{D} \beta \mathrm{H}, \mathrm{NET}$ and MAO-A are present in capsaicin-sensitive nociceptive neurons, lumbar dorsal root ganglia were harvested from groups of 2 control and 4 neonatal capsaicin-treated 6-week-old rats. Tissue from all rats was processed in parallel and PCR amplifications of respective cDNA were performed in duplicate, for 3 independent experiments and pair of values averaged.

Total RNA, from $\mathrm{L}_{4}-\mathrm{L}_{6}$ dorsal root ganglia of control and neonatal capsaicin-treated rats, was extracted with Trizol (Invitrogen). For semi-quantitative RT-PCR, RNA was quantified with a spectrophotometer (UV160, Shimadzu) and reverse transcriptions were carried out using $1 \mu \mathrm{g}$ of total RNA and the reverse transcriptase Superscript II (Invitrogen). Equal amount of cDNA $(2 \mu \mathrm{g})$ was used in each PCR reaction. The PCR primers (Invitrogen) used were as follows: for D $\beta \mathrm{H}$ (accession number NM_013158), Forward 5'-

ACAGAGGGTGTCAAACAGCCTATC-3' and Reverse 5'ATGATGATGTGGTGTCGGGG-3'; for MAO-A (accession number XM_343764), Forward 5'-TGCCATCCCACCGATTTTG-3' and Reverse 5'GCAGTGACCCATCTGGTTTAGTGTC-3'; and for NET (accession number NM_031343) Forward 5'-GAAGCCATTTCTACTCTGTCGGG-3' and Reverse 5'-

ACCTGTCCACGCCATAAAACC-3'. To perform semi-quantitative PCR, Quantum RNA $^{\text {TM }} 18 \mathrm{~S}$ internal standard (Ambion) was used in all reactions. Pilot experiments were performed to optimize the number of cycles and the ratio of competimers (specially modified primers that cannot be extended) necessary to obtain amplification of the $18 \mathrm{~S}$ ribosomal RNA band to the same linear range as the 3 RNAs of interest. Twenty-five $\mu l$ of the PCR products were separated on $2 \%$ agarose gels and visualized with ethidium bromide. Images of the gels were acquired with a Chemilmager system and analyzed with AlphaEaseFC software (Alpha Innotech, San Leandro, CA). 


\section{Measuring catecholamines}

Knee joint perfusion-Knee joints of alcohol-naïve, double-surgery control diet, and double-surgery alcohol-fed rats, were perfused, in vivo, at a rate of $250 \mu \mathrm{l} / \mathrm{min}$, as previously described (Green et al., 1998; Miao et al., 2000; Miao et al., 2001; Green \& Levine, 2005), with saline alone or saline containing capsaicin $(5 \mathrm{mg} / \mathrm{ml})$. The perfusate was collected at 5min intervals, for $1 \mathrm{hr}$ and catecholamine content measured. Oxidation of catecholamines was minimized by addition of sodium metabisulphite.

Measurement of catecholamine levels-Catecholamines were extracted from knee joint perfusate by the alumina adsorption method, and catecholamine content determined using HPLC with electrochemical detection (ESA 5200 electrochemical detector, ESA Inc., Bedford, MA (Khasar et al., 2003)).

\section{Western blot analysis}

Saphenous nerves in anesthetized rats were ligated with a 4-0 silk surgical suture, $1 \mathrm{~cm}$ above the nerve's knee-level bifurcation. Ligation was performed to dam proteins transported from the cell body to the periphery (Glazer \& Basbaum, 1980; Chikuma et al., 2007), enriching them proximal to the ligation to increase their detectability. On the fourth day following initiation of oligodeoxynucleotide (ODN) treatment, a 5-mm section of saphenous nerve, proximal to the ligation, was harvested. The membrane was probed with affinity-purified polyclonal anti-norepinephrine transporter antibody (1/200, AB5066P, CHEMICON $^{\circledR}$ international, Temecula, CA) followed by incubation with Biotin-SPconjugated affinipure goat anti-rabbit IgG (1/1000, Jackson Immuno Research, West Grove, PA) and a final incubation with Strepdavidin-peroxidase (1/500, Sigma, St Louis, MO). To normalize the loaded samples, affinity purified mouse monoclonal anti-GAPDH antibody (1/5000, Abcam) was used followed by incubation with HRP-conjugated goat anti-mouse $\operatorname{IgG}(1 / 10,000$, Pierce Biotechnology). Membranes were incubated with enhanced chemiluminescence reagents (Pierce Biotechnology) and images of the membrane were acquired with CHEMILMAGER ${ }^{\mathrm{TM}}$ chemiluminescence imaging system and analyzed with AlphaEaseFC ${ }^{\text {TM }}$ sofware (Alpha Innotech Corporation, San Leandro, CA).

\section{Assessing the functional role of catecholamines}

Administration of monoamine oxidase and NET inhibitors-To determine if MAO metabolites of catecholamines contribute to ethanol-induced hyperalgesia, we administered isoform-selective MAO isozyme inhibitors: clorgyline ( $2 \mathrm{mg} / \mathrm{kg} /$ day, s.c.) for MAO-A, or pargyline ( $25 \mathrm{mg} / \mathrm{kg} /$ day, s.c.) for MAO-B (Mega et al., 2002). To determine if catecholamine transport was required for ethanol-induced neuropathy we treated rats with the NET inhibitor desipramine $(20 \mathrm{mg} / \mathrm{kg} /$ day, s.c. $)$. To determine if inhibition of MAO or NET would reverse already established ethanol-induced hyperalgesia, administration of MAO inhibitors or desipramine was begun after 3 weeks of ethanol consumption. To test if inhibition of MAO or NET would delay or prevent the development of ethanol-induced hyperalgesia, inhibitor administration was started at the same time as ethanol diet. Finally, to test the hypothesis that MAO or NET inhibitors produce their effects by action in the periphery, we tested the effect of clorgyline (100 ng) or desipramine (10 ng to $1 \mu \mathrm{g}$ ) injected intradermally in the hind paw at the site of nociceptive testing; paw withdrawal threshold was measured before and at 30-min intervals after drug administration.

NET antisense-To confirm that the effect of desipramine was at NET, we attenuated NET in the peripheral nerve by intrathecal administration of oligodeoxynucleotide (ODN) antisense to NET. The NET ODN antisense sequence, 5'-AGA CAT CGG GAA AGG TTG $-3^{\prime}$ (Invitrogen Life technologies, Carlsbad, CA), was directed against a unique region of the 
rat sequence (GeneBank accession number NM_031343). The mismatch ODN sequence was designed by mismatching 7 bases (denoted by bold face) of the antisense sequence: $5^{\prime}$ - TCA CAT CCC GAA ACC TTC - $3^{\prime}$. ODN was administered into the spinal intrathecal space at a dose of $40 \mu \mathrm{g} / 20 \mu \mathrm{l}$, once a day for 5 days, as described previously (Alessandri-Haber et al., 2003). To determine if NET antisense treatment would reverse already established ethanolinduced hyperalgesia, ethanol was first given for 3 weeks to establish hyperalgesia. Then antisense or mismatch was administered for 5 days.

\section{Administration of DOPEGAL}

We evaluated the effect of DOPEGAL injected into the hind paw of control-diet rats, on mechanical nociceptive threshold. DOPEGAL $(0.1 \mathrm{ng}-1.0 \mu \mathrm{g})$ was injected intradermally at the site of nociceptive testing on the dorsum of the hind paw, using separate groups of rats for each dose, and paw-withdrawal threshold measured at 0.5, 4, 24 and 48 hours after injection.

\section{Statistical Analysis}

Group data, presented as mean \pm SEM, were analyzed using repeated measures analysis of variance (ANOVA), 1-way ANOVA or Student's t-test, as appropriate. The accepted level for significance was $\mathrm{p}<0.05$.

\section{Results}

\section{Catecholamine mechanisms in primary afferent neurons}

Catecholamines in sensory neurons-To determine if catecholamines are present in nociceptors, we first measured epinephrine levels in perfusate of capsaicin-stimulated rat knee-joints. To ensure that releasable pools of catecholamines did not originate from postganglionic sympathetic neurons, we performed experiments in sympathectomized animals. Furthermore, to eliminate a contribution of adrenal-derived catecholamines, the rats also underwent adrenal medullectomy, "double-surgery" (see Materials and Methods). To confirm the efficacy of surgical sympathectomy, dorsal root ganglia, which have rich sympathetic innervation, were examined for tyrosine hydroxylase-containing neuronal profiles. As shown in Figure 2A, 14 days after sympathectomy, dorsal root ganglia exhibited only rare tyrosine hydroxylase immunoreactive profiles, most of which appeared to be degenerating. As shown in Table 1, when capsaicin, a sensory neuron excitotoxin, was added to the knee joint perfusion fluid, there was a marked increase in epinephrine in the perfusate. Compared to perfusate from capsaicin-stimulated knees in control-diet rats $(n=$ 10 ), there was an approximately 3 -fold increase in epinephrine concentration in those fed ethanol diet $(\mathrm{p}<0.05 ; \mathrm{n}=10)$. Although we were able to detect norepinephrine in the knee joint perfusate of ethanol-fed "double surgery" rats (saline alone, $28 \pm 9 \mu \mathrm{g} / \mathrm{ml}(\mathrm{n}=10)$; saline + capsaicin, $38 \pm 12 \mu \mathrm{g} / \mathrm{ml}(\mathrm{n}=10))$, suggesting the presence of a releasable pool of norepinephrine in sensory neurons of the knee joint. That the level was much lower than that of epinephrine, possibly reflects metabolic conversion of norepinephrine to epinephrine and/ or the degree to which uptake of epinephrine contributes to the capsaicin releasable pool. Dopamine was not detected.

Expression of D $\beta H$, NET and MAO-A mRNA-Catecholaminergic markers are difficult to detect in dorsal root ganglion neurons by immunohistochemistry. For example, the percentage of tyrosine hydroxylase-positive neurons reported varies markedly between studies (Katz et al., 1983; Price \& Mudge, 1983; Price, 1985; Katz \& Black, 1986; Katz et al., 1987; Vega et al., 1991; Brumovsky et al., 2006). Therefore we have pursued this question with a more sensitive technique, semiquantitative RT-PCR, in dorsal root ganglion neurons obtained from control rats and rats treated neonatally with capsaicin, to destroy 
nociceptors. The presence of mRNA for $\mathrm{D} \beta \mathrm{H}$, NET, and MAO-A was detected in dorsal root ganglion neurons. As shown in Figure 2B, the levels of D $\beta \mathrm{H}$ and MAO-A were decreased by $47 \pm 3 \%$ and $54 \pm 5 \%$, respectively, by capsaicin treatment, whereas NET was not altered.

\section{Role of toxic catecholamine metabolites in ethanol-induced neuropathic hyperalgesia}

Because we found evidence that at least some nociceptive primary afferent neurons possess enzymes that would enable them to metabolize catecholamines, we tested our principal hypothesis that catecholamine metabolites play a role in the neuronal dysfunction that underlies ethanol-induced hyperalgesia. As reported previously (Dina et al., 2006), rats fed ethanol diet, on a "4-day on/3-day off" binge-drinking protocol, for 3 weeks, exhibit significantly reduced mechanical nociceptive thresholds compared to control-diet rats.

Does ethanol-induced hyperalgesia depend on catecholamine metabolism?The role of catecholamine metabolites in alcohol-induced mechanical hyperalgesia was first assessed by evaluating the effect of inhibiting MAO enzymes, which metabolize catecholamines. In rats that consumed ethanol at the same time as they were treated with MAO-A inhibitor, mechanical thresholds did not decrease, compared to rats treated with the MAO-B inhibitor, or to rats that consumed ethanol but did not receive a MAO-A inhibitor (both $\mathrm{p}<0.001$; Fig. 3A). In addition, fully developed hyperalgesia (following 3 weeks on ethanol diet) was reversed by administration of the MAO-A inhibitor clorgyline $(2 \mathrm{mg} / \mathrm{kg} /$ day s.c.), but not by the MAO-B inhibitor, pargyline ( $25 \mathrm{mg} / \mathrm{kg} /$ day s.c; Fig. 3B). Furthermore, intradermal administration of clorgyline $(100 \mathrm{ng})$ at the site of nociceptive testing on the dorsum of the hind paw, also reversibly inhibited the hyperalgesic effect of alcohol consumption (Fig. 3C).

\section{Is the catecholamine metabolite DOPEGAL sufficient to produce}

hyperalgesia?-Because epinephrine and norepinephrine are preferentially metabolized by MAO-A (Waldmeier et al., 1976; Rivett et al., 1982), and the MAO-A inhibitor reduced ethanol hyperalgesia, we tested the effect on nociception of the MAO-A catecholamine metabolite implicated in neurodegenerative diseases of the CNS (Burke et al., 1999; Burke et al., 2004; Marchitti et al., 2007), DOPEGAL. As shown in Figure 4, intradermal injection of DOPEGAL ( $0.1 \mathrm{ng}-1.0 \mu \mathrm{g})$ in the dorsum of the hind paw, produced time- and dosedependent mechanical hyperalgesia. Of note, by $48 \mathrm{hr}$ after injection, the magnitude of the mechanical hyperalgesia produced by a low dose of DOPEGAL $(1 \mathrm{ng})$ reached the same maximum severity as a $1 \mu \mathrm{g}$, suggesting a potent time-dependent effect of even a very low dose of DOPEGAL.

\section{Importance of catecholamine uptake in ethanol-induced hyperalgesia}

In neurodegenerative diseases in the CNS, accumulation of catecholamines by uptake from the extracellular space can be a source of catecholamine substrate for MAO-A production of toxic metabolites (Burke et al., 1999; Burke et al., 2004; Marchitti et al., 2007). To test if a catecholamine uptake-mediated mechanism contributes to pain associated with alcoholic neuropathy, we assessed the effect of reducing the NET-mediated catecholamine uptake mechanism on ethanol-induced hyperalgesia. As shown in Figure 5A, administration of the NET inhibitor, desipramine $(20 \mathrm{mg} / \mathrm{kg} / \mathrm{day}$, s.c. $)$, to rats that had been fed the ethanol diet for 3 weeks and had developed hyperalgesia, attenuated the hyperalgesia. Intradermal injection of desipramine at the site of nociceptive testing also attenuated ethanol-induced hyperalgesia (Fig. 5B), suggesting a peripheral site of action. To confirm that these actions of desipramine were due to inhibition of NET, we also examined whether knockdown of NET could reduce ethanol-induced hyperalgesia. As shown in Figure 6A, intrathecal administration of NET antisense for 5 days, in rats fed ethanol diet for 3 weeks, reversed 
ethanol-induced hyperalgesia, and the hyperalgesia was fully recovered 4 days after the last injection of NET antisense. As shown in Figure 6B, NET antisense was effective in producing a $34 \pm 3 \%$ reduction in an $80-\mathrm{kDa}$ band (corresponding to the molecular weight of NET) detected by Western blot analysis in saphenous nerve of antisense- compared with mismatch-treated rats ( $\mathrm{n}=5$ for each group, $\mathrm{p}=0.01$, unpaired Student's $t$-test).

\section{Discussion}

Pain states associated with peripheral neuropathies of diverse etiology, such as those induced by chronic alcohol consumption, diabetes, and chemotherapy for cancer and AIDS, are among the most intractable of pain syndromes. This is due, in part, to our lack of knowledge concerning the underlying mechanisms, which would enable the development of therapies designed to target the pathophysiological causes of these pain syndromes.

The present study tested the idea that catecholaminergic mechanisms that have been implicated in neurodegenerative diseases in the central nervous system might provide insight into the mechanisms of peripheral neuropathy. Specifically, some small-diameter sensory neurons in rodents express tyrosine hydroxylase (Katz et al., 1983; Price \& Mudge, 1983; Price, 1985; Katz \& Black, 1986; Katz et al., 1987; Vega et al., 1991; Brumovsky et al., 2006) and MAO (Vega et al., 1991). Since some forms of painful peripheral neuropathy (e.g., alcoholic peripheral neuropathy) are associated with marked increases in plasma catecholamines (Patterson-Buckendahl et al., 2004; Patterson-Buckendahl et al., 2005), we tested the hypothesis that metabolites of catecholamines contribute to ethanol-induced painful peripheral neuropathy.

Our observation that capsaicin stimulates the release of catecholamines in the knee joint, after sympathetic innervation has been eliminated, suggests that the catecholamine detected is derived from nociceptive sensory nerve endings. Failure of previous studies to detect catecholamines in primary afferents may have been due to: 1) use of a less sensitive assay method, for example glyoxylic acid staining (Katz et al., 1987; Kummer et al., 1990), 2) requirement for uptake of extracellular catecholamines which are generally low, except under certain conditions such as alcohol dependence (Patterson-Buckendahl et al., 2005), and 3) possible requirement for a concomitant toxic injury to the sensory neurons produced by a direct neurotoxic action of ethanol (Fadda \& Rossetti, 1998; Schuchardt, 2000; Koike et al., 2001; Zambelis et al., 2005; Koike \& Sobue, 2006). Our studies do not establish to what degree the pool of releasable catecholamine originates from synthesis within nociceptors or from their uptake from the extracellular space. However, our observation that ethanol-induced hyperalgesia is reduced by both pharmacologic and antisense inhibition of NET suggests that uptake plays a role.

It has been suggested that tyrosine hydroxylase in sensory neurons could reflect a dopaminergic phenotype (Price \& Mudge, 1983; Price, 1985; Vega et al., 1991) and dopamine can be metabolized by MAO-A. However, we did not detect dopamine in the perfusate of capsaicin-stimulated knee joints. Instead, our demonstration of a capsaicinreleasable pool of catecholamines suggests that the products of tyrosine hydroxylase metabolism in primary afferent nociceptors largely continue along the enzymatic pathway for production of norepinephrine and epinephrine. Furthermore, the increased release of epinephrine from nociceptors in ethanol-fed rats suggests the ability of chronic ethanol consumption to increase catecholamine content in nociceptors. Thus, our data support the idea that sensory neurons possess mechanisms for catecholamine uptake, metabolism and release that could contribute to the pathology of ethanol-induced pain. However, we cannot conclude that such sensory neurons express a fully functional catecholaminergic phenotype. 
Previous studies have demonstrated tyrosine hydroxylase and MAO immunoreactivity in a small percentage of adult sensory neurons (Katz et al., 1983; Price \& Mudge, 1983; Price, 1985; Katz \& Black, 1986; Katz et al., 1987; Vega et al., 1991; Brumovsky et al., 2006), but other investigators have failed to detect these (Czaja, 2000) or other markers of a catecholaminergic phenotype (Katz et al., 1983; Price \& Mudge, 1983; Price, 1985; Vega et al., 1991). It has been suggested that this failure may be due to a general difficulty in detecting such proteins in sensory neurons by immunocytochemistry (Brumovsky et al., 2006). Therefore, we used a very sensitive and highly specific technique, semiquantitative RT-PCR. Using this technique, we found mRNA for MAO-A, D $\beta H$ and NET in dorsal root ganglia. The expression of MAO-A and $\mathrm{D} \beta \mathrm{H}$ specifically in nociceptive sensory neurons is suggested by our demonstration of neonatal capsaicin treatment, to selectively destroy nociceptors, decreased by approximately half, levels of mRNA for D $\beta \mathrm{H}$ and MAO-A. A capsaicin-induced decrease in NET could not be established by semiquantitative RT-PCR; whether this is due, for example to extensive expression of NET in other cells in the ganglion (Shearman \& Meyer, 1999; Sieber-Blum \& Ren, 2000; Eisenhofer, 2001; Ren et al., 2003; Thackeray et al., 2007; Kiyono et al., 2008), remains to be determined. Of note in this regard, NET expression is regulated by a variety of signals, (Paczkowski et al., 1996; Jahng et al., 1998; Zahniser \& Doolen, 2001; Hara et al., 2002; Mao et al., 2005; Habecker et al., 2006), including glucocorticoids (Grundemann et al., 1998; Eisenhofer, 2001). Thus, it is possible that NET, in the adult DRG, from rats treated neonatally with capsaicin, was upregulated in other cells. However, intrathecal antisense-induced attenuation of NET expression in the saphenous nerve, and attenuation of mechanical hyperalgesia by both NET antisense ODN and by the NET inhibitor desipramine, support the suggestion that some of the epinephrine available to MAO-A in sensory neurons is taken up from extracellular sources. Western blot analysis, showing knock down of NET expression (and other proteins) in the saphenous nerve, may be an underestimate of the decrease of this protein in the sensory neurons, compared to the almost complete attenuation of mechanical hyperalgesia by intrathecal antisense. Given that diverse cell types express NET (Shearman \& Meyer, 1999; Sieber-Blum \& Ren, 2000; Eisenhofer, 2001; Ren et al., 2003; Thackeray et al., 2007; Kiyono et al., 2008), spinal intrathecal administration of ODN antisense to NET would not be expected to attenuate NET expression in these other cells. Thus, the inability of other cells, as opposed to sensory neurons, to respond to antisense might account for the apparent discrepancy between the magnitude of attenuation of symptoms and decrease in NET expression.

Intradermal injection of the neurotoxic MAO-A metabolite DOPEGAL produced mechanical hyperalgesia in behavioral tests of nociception. This finding supports the suggestion that this particular MAO-A catecholamine metabolite plays a role in the symptoms of painful peripheral neuropathy. Therefore, a novel therapy for some forms of neuropathic pain could be based on the use of MAO inhibitors, particularly inhibitors that cannot penetrate the blood brain barrier, since they produce many of their dose-limiting side effects in the CNS.

Since MAO-A is located within mitochondria (Student \& Edwards, 1977; Westlund et al., 1993), we speculate that neurotoxicity of MAO-A metabolites may involve mitochondrial mechanisms, which have been implicated in peripheral neuropathy (Leinninger et al., 2006; Baloh, 2007; Liu et al., 2007). Caspase signaling and mitochondrial electron transport (Joseph \& Levine, 2004; 2006), as well as reactive oxygen species generation (Naik et al., 2006; Siniscalco et al., 2007), have been shown to play a role in models of neuropathic pain. However, upstream pathways that activate these mitochondrial mechanisms have remained elusive. We suggest that intracellular metabolism of catecholamines may provide one such pathway that would initiate mitochondrial damage. 
In summary, we have studied the role of catecholamine metabolites in painful peripheral neuropathy. We have provided evidence that: 1) primary afferent nociceptors may synthesize and release catecholamines, 2) primary afferent nociceptors possess the necessary machinery for uptake and metabolism of catecholamines and 3) the toxic catecholamine metabolite DOPEGAL produces potent mechanical hyperalgesia. These findings are consistent with the suggestion that metabolism of catecholamines by sensory neurons contributes to a painful peripheral neuropathy. Better understanding of this mechanism could provide targets for the development of novel therapies for the treatment of neuropathic pain associated with alcoholism and other toxic neuropathies.

\section{Acknowledgments}

We are grateful to Mr. Dennis Mendoza for technical assistance. This study was supported by NIH/NIAAA Grant \#R01 AA013875 and the Alcoholic Beverage Medical Research Foundation.

\section{Abbreviations}

$\begin{array}{ll}\text { DßH } & \text { dopamine beta hydoxylase } \\ \text { DOPEGAL } & \text { 3,4-dihydroxyphenylglycolaldehyde } \\ \text { ED } & \text { ethanol diet } \\ \text { MAO } & \text { Monoamine oxidase } \\ \text { NET } & \text { norepinephrine transporter } \\ \text { ODN } & \text { Oligodeoxynucleotide } \\ \text { RT-PCR } & \text { reverse transcriptase polymerase chain reaction }\end{array}$

\section{References}

Alessandri-Haber N, Yeh JJ, Boyd AE, Parada CA, Chen X, Reichling DB, Levine JD. Hypotonicity induces TRPV4-mediated nociception in rat. Neuron. 2003; 39:497-511. [PubMed: 12895423]

Baloh RH. Mitochondrial Dynamics and Peripheral Neuropathy. Neuroscientist. 2007

Baron R, Janig W, Kollmann W. Sympathetic and afferent somata projecting in hindlimb nerves and the anatomical organization of the lumbar sympathetic nervous system of the rat. J Comp Neurol. 1988; 275:460-468. [PubMed: 3225349]

Brain, L.; Walton, JN. In: Brain's Diseases of the Nervous System. Oxford University Press; London, New York: 1969. Disorders of Peripheral Nerves: Alcoholic Polyneuritis; p. 817-819.

Brumovsky P, Villar MJ, Hokfelt T. Tyrosine hydroxylase is expressed in a subpopulation of small dorsal root ganglion neurons in the adult mouse. Exp Neurol. 2006; 200:153-165. [PubMed: 16516890]

Burke WJ, Li SW, Chung HD, Ruggiero DA, Kristal BS, Johnson EM, Lampe P, Kumar VB, Franko M, Williams EA, Zahm DS. Neurotoxicity of MAO metabolites of catecholamine neurotransmitters: role in neurodegenerative diseases. Neurotoxicology. 2004; 25:101-115. [PubMed: 14697885]

Burke WJ, Li SW, Schmitt CA, Xia P, Chung HD, Gillespie KN. Accumulation of 3,4dihydroxyphenylglycolaldehyde, the neurotoxic monoamine oxidase A metabolite of norepinephrine, in locus ceruleus cell bodies in Alzheimer's disease: mechanism of neuron death. Brain Res. 1999; 816:633-637. [PubMed: 9878889]

Chen X, Levine JD. Mechanically-evoked C-fiber activity in painful alcohol and AIDS therapy neuropathy in the rat. Molecular pain. 2007; 3:5. [PubMed: 17319957]

Chikuma T, Shimizu M, Tsuchiya Y, Kato T, Hojo H. Axonal transports of tripeptidyl peptidase II in rat sciatic nerves. Neurochem Int. 2007; 50:236-242. [PubMed: 17023090]

Creange A. The diagnosis of acquired sensory neuropathies. Revue neurologique. 2004; 160:363-370. [PubMed: 15037854] 
Czaja K. Distribution of primary afferent neurons innervating the porcine oviduct and their immunohistochemical characterization. Cells, tissues, organs. 2000; 166:275-282. [PubMed: 10765023]

Dina OA, Barletta J, Chen X, Mutero A, Martin A, Messing RO, Levine JD. Key role for the epsilon isoform of protein kinase C in painful alcoholic neuropathy in the rat. J Neurosci. 2000; 20:86148619. [PubMed: 11069970]

Dina OA, Chen X, Reichling D, Levine JD. Role of protein kinase Cepsilon and protein kinase A in a model of paclitaxel-induced painful peripheral neuropathy in the rat. Neuroscience. 2001; 108:507-515. [PubMed: 11738263]

Dina OA, Khasar SG, Alessandri-Haber N, Green PG, Messing RO, Levine JD. Alcohol-induced stress in painful alcoholic neuropathy. Eur J Neurosci. 2008; 27:83-92. [PubMed: 18093169]

Dina OA, Messing RO, Levine JD. Ethanol withdrawal induces hyperalgesia mediated by PKCepsilon. Eur J Neurosci. 2006; 24:197-204. [PubMed: 16800864]

Dina OA, Parada CA, Yeh J, Chen X, McCarter GC, Levine JD. Integrin signaling in inflammatory and neuropathic pain in the rat. Eur J Neurosci. 2004; 19:634-642. [PubMed: 14984413]

Eisenhofer G. The role of neuronal and extraneuronal plasma membrane transporters in the inactivation of peripheral catecholamines. Pharmacology \& therapeutics. 2001; 91:35-62. [PubMed: 11707293]

Eisenhofer G, Kopin IJ, Goldstein DS. Catecholamine metabolism: a contemporary view with implications for physiology and medicine. Pharmacological reviews. 2004; 56:331-349. [PubMed: 15317907]

Fadda F, Rossetti ZL. Chronic ethanol consumption: from neuroadaptation to neurodegeneration. Prog Neurobiol. 1998; 56:385-431. [PubMed: 9775400]

Flatmark T. Catecholamine biosynthesis and physiological regulation in neuroendocrine cells. Acta Physiol Scand. 2000; 168:1-17. [PubMed: 10691773]

Freeman R. Autonomic peripheral neuropathy. Lancet. 2005; 365:1259-1270. [PubMed: 15811460]

Freeman R. Autonomic peripheral neuropathy. Neurologic clinics. 2007; 25:277-301. [PubMed: 17324728]

Glazer, EJ.; Basbaum, AI. Science. Vol. 208. New York, N.Y: 1980. Leucine enkephalin: localization in and axoplasmic transport by sacral parasympathetic preganglionic neurons; p. 1479-1481.

Green PG, Levine JD. Sexual dimorphism in the effect of nonhabituating stress on neurogenic plasma extravasation. Eur J Neurosci. 2005; 21:486-492. [PubMed: 15673447]

Green PG, Miao FJ, Strausbaugh H, Heller P, Janig W, Levine JD. Endocrine and vagal controls of sympathetically dependent neurogenic inflammation. Ann N Y Acad Sci. 1998; 840:282-288. [PubMed: 9629256]

Grundemann D, Schechinger B, Rappold GA, Schomig E. Molecular identification of the corticosterone-sensitive extraneuronal catecholamine transporter. Nat Neurosci. 1998; 1:349-351. [PubMed: 10196521]

Habecker BA, Willison BD, Shi X, Woodward WR. Chronic depolarization stimulates norepinephrine transporter expression via catecholamines. J Neurochem. 2006; 97:1044-1051. [PubMed: 16573647]

Hara K, Minami K, Ueno S, Toyohira Y, Tsutsui M, Shigematsu A, Yanagihara N. Up-regulation of noradrenaline transporter in response to prolonged exposure to ketamine. Naunyn Schmiedebergs Arch Pharmacol. 2002; 365:406-412. [PubMed: 12012027]

Hoitsma E, Reulen JP, de Baets M, Drent M, Spaans F, Faber CG. Small fiber neuropathy: a common and important clinical disorder. Journal of the neurological sciences. 2004; 227:119-130. [PubMed: 15546602]

Hucho TB, Dina OA, Kuhn J, Levine JD. Estrogen controls PKCepsilon-dependent mechanical hyperalgesia through direct action on nociceptive neurons. Eur J Neurosci. 2006; 24:527-534. [PubMed: 16836642]

Jahng JW, Houpt TA, Joh TH, Son JH. Differential expression of monoamine oxidase A, serotonin transporter, tyrosine hydroxylase and norepinephrine transporter mRNA by anorexia mutation and food deprivation. Brain research. 1998; 107:241-246. [PubMed: 9593916] 
Jamieson SM, Liu J, Connor B, McKeage MJ. Oxaliplatin causes selective atrophy of a subpopulation of dorsal root ganglion neurons without inducing cell loss. Cancer chemotherapy and pharmacology. 2005; 56:391-399. [PubMed: 15887017]

Joseph EK, Levine JD. Caspase signalling in neuropathic and inflammatory pain in the rat. Eur J Neurosci. 2004; 20:2896-2902. [PubMed: 15579143]

Joseph EK, Levine JD. Mitochondrial electron transport in models of neuropathic and inflammatory pain. Pain. 2006; 121:105-114. [PubMed: 16472913]

Katz DM, Adler JE, Black IB. Catecholaminergic primary sensory neurons: autonomic targets and mechanisms of transmitter regulation. Federation proceedings. 1987; 46:24-29. [PubMed: 2879746]

Katz DM, Black IB. Expression and regulation of catecholaminergic traits in primary sensory neurons: relationship to target innervation in vivo. J Neurosci. 1986; 6:983-989. [PubMed: 2422331]

Katz DM, Markey KA, Goldstein M, Black IB. Expression of catecholaminergic characteristics by primary sensory neurons in the normal adult rat in vivo. Proceedings of the National Academy of Sciences of the United States of America. 1983; 80:3526-3530. [PubMed: 6134285]

Keller NR, Diedrich A, Appalsamy M, Tuntrakool S, Lonce S, Finney C, Caron MG, Robertson D. Norepinephrine transporter-deficient mice exhibit excessive tachycardia and elevated blood pressure with wakefulness and activity. Circulation. 2004; 110:1191-1196. [PubMed: 15337696]

Kerstens HM, Poddighe PJ, Hanselaar AG. A novel in situ hybridization signal amplification method based on the deposition of biotinylated tyramine. J Histochem Cytochem. 1995; 43:347-352. [PubMed: 7897179]

Khasar SG, Green PG, Miao FJ, Levine JD. Vagal modulation of nociception is mediated by adrenomedullary epinephrine in the rat. Eur J Neurosci. 2003; 17:909-915. [PubMed: 12603283]

Khasar SG, Miao FJ, Gear RW, Green PG, Isenberg WM, Levine JD. Sympathetic-independent bradykinin mechanical hyperalgesia induced by subdiaphragmatic vagotomy in the rat. J Pain. 2002; 3:369-376. [PubMed: 14622740]

Khasar SG, Miao FJ, Janig W, Levine JD. Vagotomy-induced enhancement of mechanical hyperalgesia in the rat is sympathoadrenal-mediated. J Neurosci. 1998; 18:3043-3049. [PubMed: 9526021]

Kiyono Y, Sugita T, Ueda M, Kawashima H, Kanegawa N, Kuge Y, Fujibayashi Y, Saji H. Evaluation of radioiodinated (2S,alphaS)-2-(alpha-(2-iodophenoxy)benzyl)morpholine as a radioligand for imaging of norepinephrine transporter in the heart. Nuclear medicine and biology. 2008; 35:213218. [PubMed: 18312831]

Koike H, Mori K, Misu K, Hattori N, Ito H, Hirayama M, Sobue G. Painful alcoholic polyneuropathy with predominant small-fiber loss and normal thiamine status. Neurology. 2001; 56:1727-1732. [PubMed: 11425941]

Koike H, Sobue G. Alcoholic neuropathy. Current opinion in neurology. 2006; 19:481-486. [PubMed: 16969158]

Kummer W, Gibbins IL, Stefan P, Kapoor V. Catecholamines and catecholamine-synthesizing enzymes in guinea-pig sensory ganglia. Cell Tissue Res. 1990; 261:595-606. [PubMed: 1978803]

Leinninger GM, Edwards JL, Lipshaw MJ, Feldman EL. Mechanisms of disease: mitochondria as new therapeutic targets in diabetic neuropathy. Nature clinical practice. 2006; 2:620-628.

Lieber CS, DeCarli LM. Liquid diet technique of ethanol administration: 1989 update. Alcohol Alcohol. 1989a; 24:197-211. [PubMed: 2667528]

Lieber CS, DeCarli LM. Recommended amounts of nutrients do not abate the toxic effects of an alcohol dose that sustains significant blood levels of ethanol. J Nutr. 1989b; 119:2038-2040. [PubMed: 2621495]

Lieber CS, DeCarli LM, Sorrell MF. Experimental methods of ethanol administration. Hepatology. 1989; 10:501-510. [PubMed: 2673971]

Liu H, Liu Z, Yang X, Huang F, Ma C, Li Z. Neurotoxicity caused by didanosine on cultured dorsal root ganglion neurons. Cell Biol Toxicol. 2007

Mao W, Iwai C, Qin F, Liang CS. Norepinephrine induces endoplasmic reticulum stress and downregulation of norepinephrine transporter density in PC12 cells via oxidative stress. American journal of physiology. 2005; 288:H2381-2389. [PubMed: 15626688] 
Marchitti SA, Deitrich RA, Vasiliou V. Neurotoxicity and metabolism of the catecholamine-derived 3,4-dihydroxyphenylacetaldehyde and 3,4-dihydroxyphenylglycolaldehyde: the role of aldehyde dehydrogenase. Pharmacological reviews. 2007; 59:125-150. [PubMed: 17379813]

Mega BT, Sheppard KW, Williams HL, McMillen BA. On the role of monoamine oxidase-A for the maintenance of the volitional consumption of ethanol in two different rat models. Naunyn Schmiedebergs Arch Pharmacol. 2002; 366:319-326. [PubMed: 12237745]

Miao FJ, Janig W, Jasmin L, Levine JD. Spino-bulbo-spinal pathway mediating vagal modulation of nociceptive-neuroendocrine control of inflammation in the rat. J Physiol. 2001; 532:811-822. [PubMed: 11313448]

Miao FJ, Janig W, Levine JD. Nociceptive neuroendocrine negative feedback control of neurogenic inflammation activated by capsaicin in the rat paw: role of the adrenal medulla. J Physiol, $527 \mathrm{Pt}$. 2000; 3:601-610.

Miao FJ, Kinnman E, Janig W, Levine JD. Variation in the anatomy of the lumbar sympathetic chain in the rat. Journal of the autonomic nervous system. 1995; 56:115-118. [PubMed: 8786273]

Naik AK, Tandan SK, Dudhgaonkar SP, Jadhav SH, Kataria M, Prakash VR, Kumar D. Role of oxidative stress in pathophysiology of peripheral neuropathy and modulation by N-acetyl-Lcysteine in rats. Eur J Pain. 2006; 10:573-579. [PubMed: 16214382]

Paczkowski NJ, Vuocolo HE, Bryan-Lluka LJ. Conclusive evidence for distinct transporters for 5hydroxytryptamine and noradrenaline in pulmonary endothelial cells of the rat. Naunyn Schmiedebergs Arch Pharmacol. 1996; 353:423-430. [PubMed: 8935709]

Patterson-Buckendahl P, Blakley G, Kubovcakova L, Krizanova O, Pohorecky LA, Kvetnansky R. Alcohol alters rat adrenomedullary function and stress response. Ann N Y Acad Sci. 2004; 1018:173-182. [PubMed: 15240366]

Patterson-Buckendahl P, Kubovcakova L, Krizanova O, Pohorecky LA, Kvetnansky R. Ethanol consumption increases rat stress hormones and adrenomedullary gene expression. Alcohol. 2005; 37:157-166. [PubMed: 16713504]

Price J. An immunohistochemical and quantitative examination of dorsal root ganglion neuronal subpopulations. J Neurosci. 1985; 5:2051-2059. [PubMed: 2410579]

Price J, Mudge AW. A subpopulation of rat dorsal root ganglion neurones is catecholaminergic. Nature. 1983; 301:241-243. [PubMed: 6130474]

Randall LO, Selitto JJ. A method for measurement of analgesic activity on inflamed tissue. Archives internationales de pharmacodynamie et de therapie. 1957; 111:409-419. [PubMed: 13471093]

Ren ZG, Porzgen PP, Youn YH, Sieber-Blum M. Ubiquitous embryonic expression of the norepinephrine transporter. Developmental neuroscience. 2003; 25:1-13. [PubMed: 12876425]

Rivett AJ, Eddy BJ, Roth JA. Contribution of sulfate conjugation, deamination, and O-methylation to metabolism of dopamine and norepinephrine in human brain. J Neurochem. 1982; 39:1009-1016. [PubMed: 6956674]

Rommelfanger KS, Weinshenker D. Norepinephrine: The redheaded stepchild of Parkinson's disease. Biochemical pharmacology. 2007; 74:177-190. [PubMed: 17416354]

Rusnak M, Gainer H. Differential effects of forskolin on tyrosine hydroxylase gene transcription in identified brainstem catecholaminergic neuronal subtypes in organotypic culture. Eur J Neurosci. 2005; 21:889-898. [PubMed: 15787695]

Schuchardt V. Alcohol and the peripheral nervous system. Therapeutische Umschau. 2000; 57:196199. [PubMed: 10804876]

Shearman LP, Meyer JS. Cocaine up-regulates norepinephrine transporter binding in the rat placenta. Eur J Pharmacol. 1999; 386:1-6. [PubMed: 10611457]

Sieber-Blum M, Ren Z. Norepinephrine transporter expression and function in noradrenergic cell differentiation. Molecular and cellular biochemistry. 2000; 212:61-70. [PubMed: 11108137]

Siniscalco D, Fuccio C, Giordano C, Ferraraccio F, Palazzo E, Luongo L, Rossi F, Roth KA, Maione $\mathrm{S}$, de Novellis V. Role of reactive oxygen species and spinal cord apoptotic genes in the development of neuropathic pain. Pharmacol Res. 2007; 55:158-166. [PubMed: 17207636]

Student AK, Edwards DJ. Subcellular localization of types A and B monoamine oxidase in rat brain. Biochemical pharmacology. 1977; 26:2337-2342. [PubMed: 597322] 
Taiwo YO, Coderre TJ, Levine JD. The contribution of training to sensitivity in the nociceptive pawwithdrawal test. Brain Res. 1989; 487:148-151. [PubMed: 2752281]

Thackeray JT, Beanlands RS, Dasilva JN. Presence of specific 11C-meta-Hydroxyephedrine retention in heart, lung, pancreas, and brown adipose tissue. J Nucl Med. 2007; 48:1733-1740. [PubMed: 17873125]

Vega JA, Amenta F, Hernandez LC, del Valle ME. Presence of catecholamine-related enzymes in a subpopulation of primary sensory neurons in dorsal root ganglia of the rat. Cell Mol Biol. 1991; 37:519-530. [PubMed: 1682049]

Waldmeier PC, Delini-Stula A, Maitre L. Preferential deamination of dopamine by an A type monoamine oxidase in rat brain. Naunyn Schmiedebergs Arch Pharmacol. 1976; 292:9-14. [PubMed: 934359]

Westlund KN, Krakower TJ, Kwan SW, Abell CW. Intracellular distribution of monoamine oxidase A in selected regions of rat and monkey brain and spinal cord. Brain Res. 1993; 612:221-230. [PubMed: 8330200]

Wilkinson CW, Shinsako J, Dallman MF. Return of pituitary-adrenal function after adrenal enucleation or transplantation: diurnal rhythms and responses to ether. Endocrinology. 1981; 109:162-169. [PubMed: 6263583]

Zahniser NR, Doolen S. Chronic and acute regulation of Na+/Cl- -dependent neurotransmitter transporters: drugs, substrates, presynaptic receptors, and signaling systems. Pharmacology \& therapeutics. 2001; 92:21-55. [PubMed: 11750035]

Zambelis T, Karandreas N, Tzavellas E, Kokotis P, Liappas J. Large and small fiber neuropathy in chronic alcohol-dependent subjects. J Peripher Nerv Syst. 2005; 10:375-381. [PubMed: 16279987] 


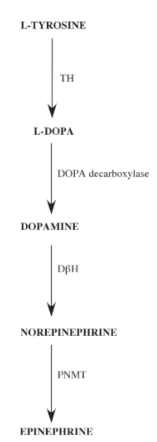

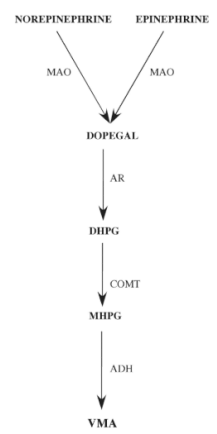

Figure 1.

A) Synthetic and B) metabolic pathways of catecholamines (Flatmark, 2000; Eisenhofer et al., 2004)

Abbreviations: ADH - alcohol dehydrogenase, AR - aldehyde reductase, COMT - catecholO-methyltransferase, D $\beta$ H - Dopamine $\beta$-hydroxylase, DHPG - 3,4-

dihydorxyphenylglycol, DOPEGAL - 3,4-dihydroxyphenylglycolaldehyde, L-DOPA dihyrdoxyphenylalanine, MAO - monoamine oxidase, MHPG - 3-methoxy-4-

hydroxyphenylglycol, PNMT - phenylethanolamine N-methyltransferase, TH - tyrosine hydroxylase, VMA - vanillylmadelic acid. 
A

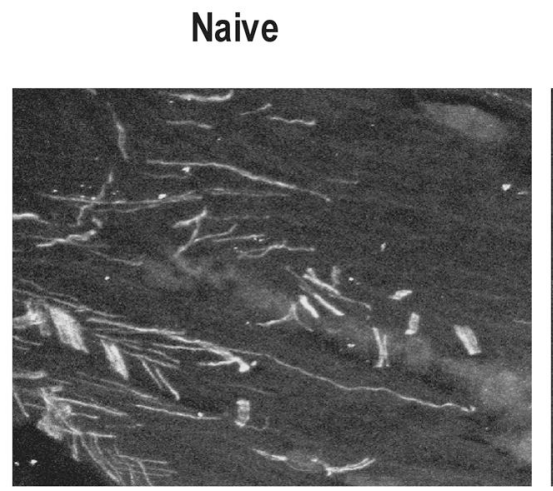

\section{Sympathectomy ( 14 days)}

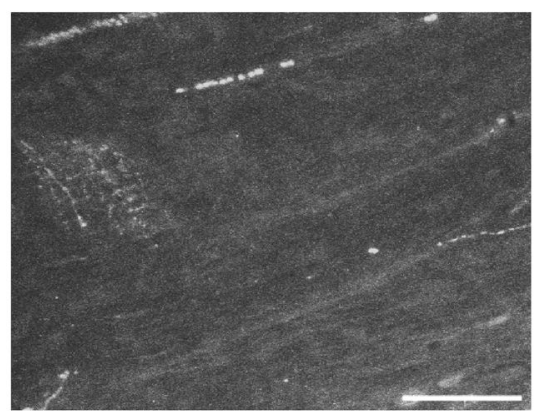

\section{B}

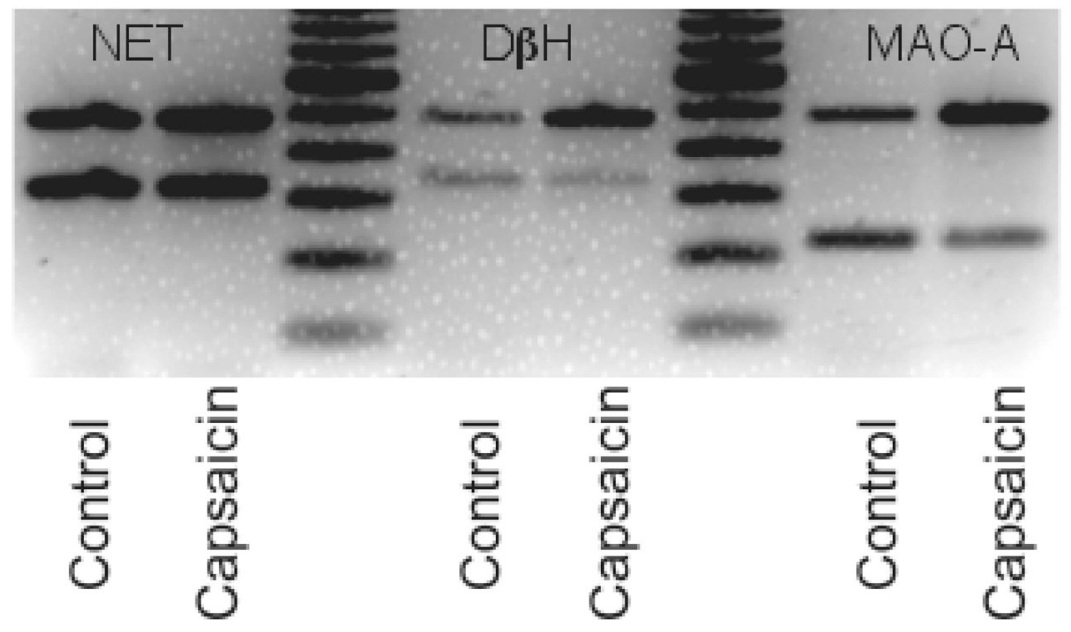

Figure 2.

Effect of lumbar surgical sympathectomy on tyrosine hydroxylase-positive profiles in lumbar dorsal root ganglia (DRG). Compared with DRG from control rats (left panel), in which tyrosine hydroxylase immunoreactive profiles were plentiful, such profiles were only rarely observed in DRG from rats that had undergone surgical lumbar sympathectomy 14 days prior, and had the appearance of degenerating axons (right panel). Scale bar $=50 \mu \mathrm{m}$. B) Semiquantitative RT-PCR for NET, DBH and MAO-A in rats that were neonatally treated with capsaicin or vehicle (control). For $\mathrm{D} \beta \mathrm{H}$, there was a $47 \pm 3 \%$ decrease $(\mathrm{p}<$ $0.001)$ and for MAO-A, there was a $54 \pm 5 \%$ decrease $(\mathrm{p}=0.002)$ in mRNA expression in capsaicin-treated rats. There was no significant change in NET mRNA expression in capsaicin-treated rats $(p>0.05)$. In each case, $n=2$ for control and $n=4$ for capsaicintreated rats (unpaired two-tailed Student's $t$ test). 


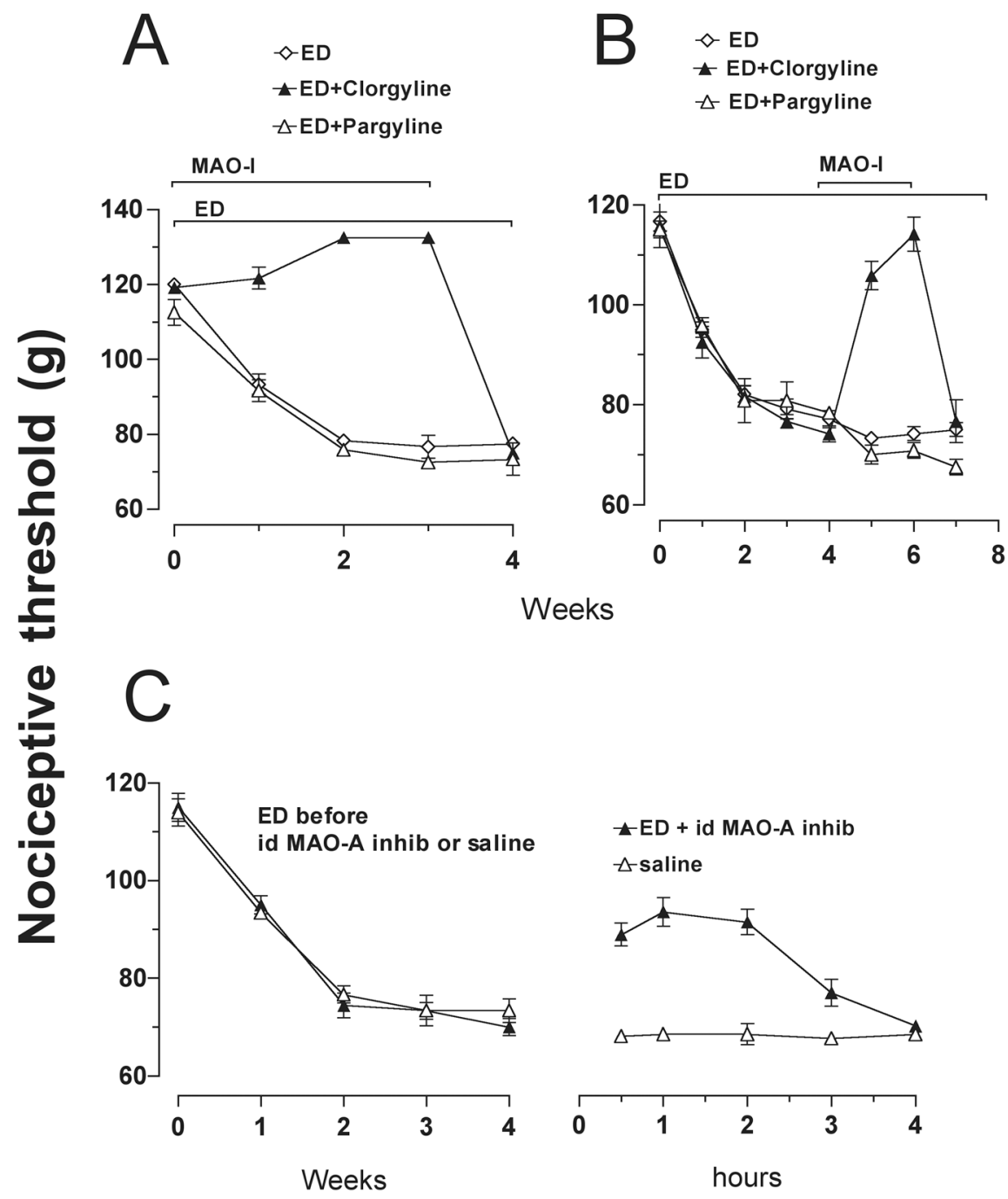

Time

Figure 3.

Effect of administration of monoamine oxidase (MAO) inhibitors, on ethanol-induced hyperalgesia. A) There was no decrease in nociceptive threshold, for up to 3 weeks, when rats were fed ethanol diet (ED) during administration of MAO-A inhibitor, clorgyline ( $2 \mathrm{mg} /$ $\mathrm{kg} /$ day subcutaneously (s.c.)) $(\mathrm{F}(2,36)=160.0, \mathrm{p}<0.001)$, until after it was stopped. The MAO-B inhibitor, pargyline $(25 \mathrm{mg} / \mathrm{kg} /$ day, s.c. $)$, did not prevent the development of ethanol-induced hyperalgesia ( $p>0.05$ ) compared with alcohol alone. B) Twelve rats were fed ED for 3 weeks, then clorgyline ( $2 \mathrm{mg} / \mathrm{kg} / \mathrm{day}$, s.c.) was administered to 4 of the rats and pargyline $(25 \mathrm{mg} / \mathrm{kg} / \mathrm{day}$ s.c.) to another 4 , while the remaining 4 received vehicle. All rats continued to be fed ED for the duration of the experiment. One week after the commencement of MAO inhibitor administration, there were significant differences between the groups $(F(2,91)=28.1, \mathrm{p}<0.001)$. Nociceptive thresholds of MAO-A but not MAO-B inhibitor-treated rats returned to about $85 \%$ of the pre-ethanol baseline after 1 week and to pre-ethanol baseline after 2 weeks ( $\mathrm{p}<0.001$ ) from weeks 5 to 6 . When MAO-A administration was stopped, ethanol-induced hyperalgesia re-appeared. C) A single 
intradermal administration of clorgyline $(100 \mathrm{ng} / 2.5 \mu \mathrm{l})$ attenuated ethanol-induced hyperalgesia for a period of about 3 hours. 


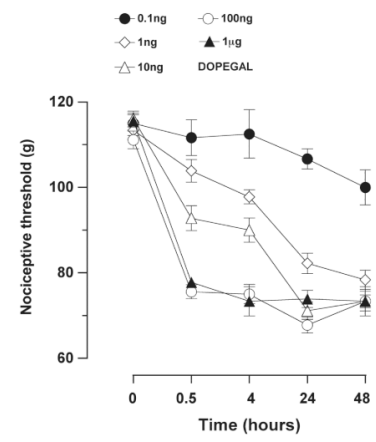

Figure 4.

Dose-response and time-dependence for the effect of DOPEGAL $(0.1 \mathrm{ng}-1.0 \mu \mathrm{g})$ on mechanical nociceptive threshold when injected intradermally into hind paws of alcoholnaïve rats. Nociceptive thresholds were measured over a period of 48 hours starting 30 minutes after injection of DOPEGAL $(F(4,60)=66.4, \mathrm{p}<0.001)$. At the first measurement, the hyperalgesic effect of DOPEGAL $(100 \mathrm{ng}$ and $1 \mu \mathrm{g})$ was already at maximum and there was no significant difference between the effects of the two doses at any time point ( $\mathrm{p}>$ $0.05, \mathrm{n}=4$ for each dose). 


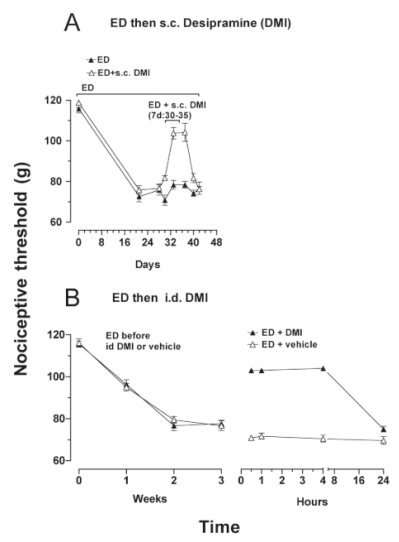

Figure 5.

A) NET inhibitor, desipramine (DMI), attenuated ethanol diet-induced hyperalgesia $(F(1,70)$ $=30.1, \mathrm{p}<0.001)$. Significant inhibition of alcohol-induced hyperalgesia occurred from days 33-37. Desipramine ( $20 \mathrm{mg} / \mathrm{kg} /$ day, s.c.) was administered, for 14 days to rats that had already been fed the ethanol diet for 3 weeks and had developed mechanical hyperalgesia. B) Reversal of ethanol-induced hyperalgesia by a single intradermal injection of desipramine (100 ng) into the hind paws of rats after 3 weeks of ethanol consumption $(\mathrm{F}(1$, $42)=507.6, \mathrm{p}<0.001)$. Alcohol-induced hyperalgesia was significantly inhibited by intradermal desipramine from 30 minutes to 4 hours. This effect of desipramine was no longer detectable after 24 hours. 

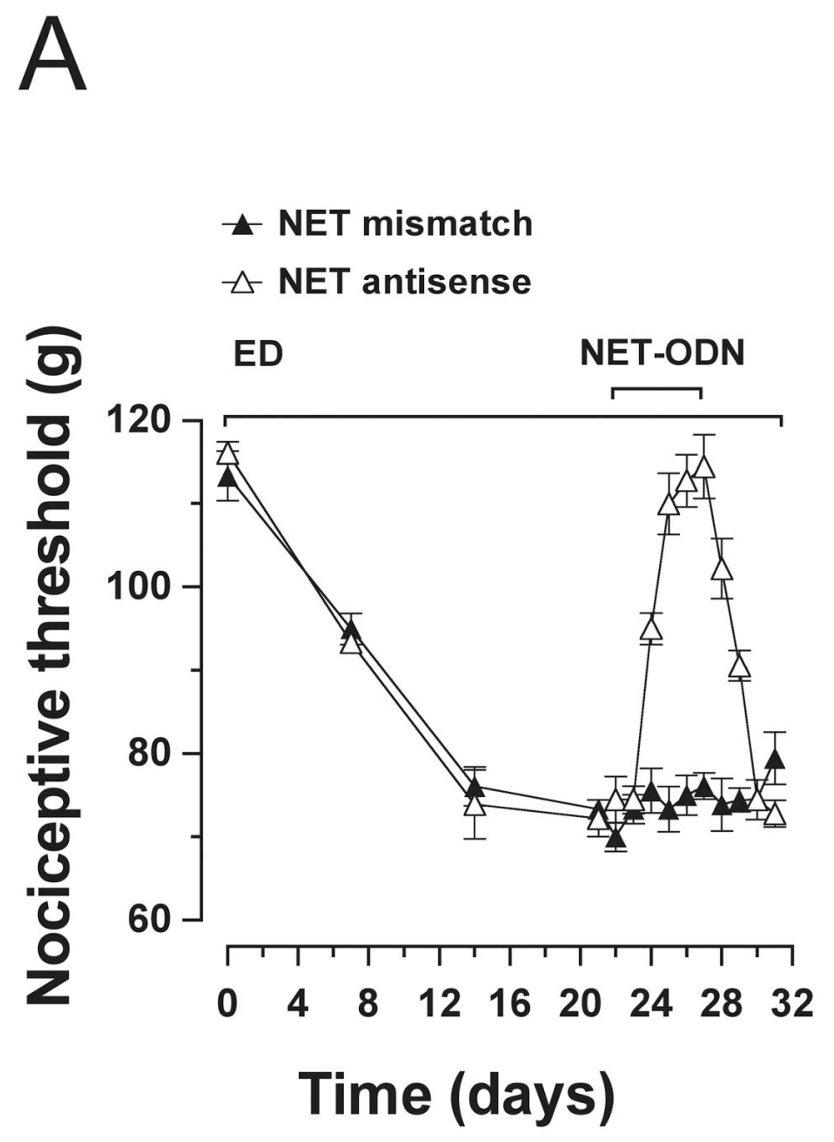

B

MM

AS

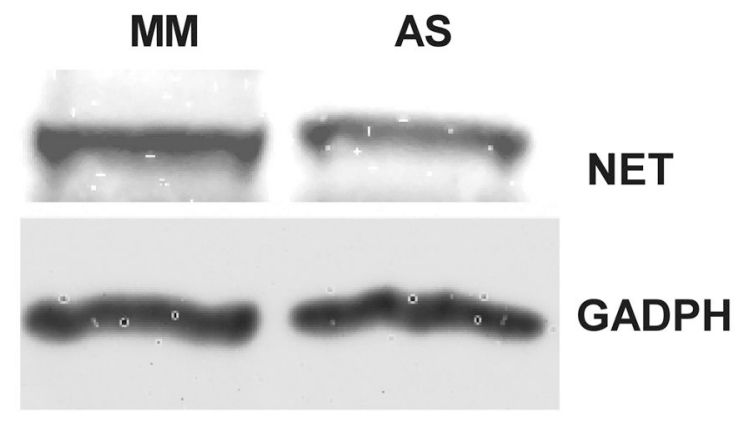

Figure 6.

A) Attenuation of ethanol-induced hyperalgesia by NET antisense. After 3 weeks of being fed ethanol diet and while still on this diet, rats were treated intrathecally with ODN antisense or mismatch to NET $(40 \mu \mathrm{g} / 20 \mu \mathrm{l})$, for 5 days. Antisense produced attenuation of alcohol-induced hyperalgesia compared to mismatch, $(\mathrm{F}(1,130)=64.30, \mathrm{p}<0.001)$.

Alcohol-induced hyperalgesia was significantly reversed from days 25-28). Three days after the last dose of antisense, hyperalgesia was re-established. B) NET antisense produced a 34 $\pm 3 \%$ reduction in a specific $80 \mathrm{kDa}$ band detected by Western blot analysis in ligated saphenous nerves compared with mismatch-treated rats $(n=5$ for each group, $p=0.01$, unpaired Student's t-test). 
Table 1

Epinephrine concentration $(\mathrm{pg} / \mathrm{ml})$ in knee joint perfusate

\begin{tabular}{|l|c|c|}
\hline \multirow{2}{*}{} & \multicolumn{2}{|c|}{ Perfusion fluid } \\
\cline { 2 - 3 } & Saline & Saline + Capsaicin \\
\hline $\begin{array}{l}\text { Control-Diet } \\
\text { Sympathectomy + Adrenal Medullectomy }\end{array}$ & $\begin{array}{c}2,119 \pm 1,302 \\
(\mathrm{n}=9)\end{array}$ & $\begin{array}{c}11,550 \pm 1,952 \\
(\mathrm{n}=10)\end{array}$ \\
\hline $\begin{array}{l}\text { Alcohol-Diet } \\
\text { Sympathectomy + Adrenal Medullectomy }\end{array}$ & $\begin{array}{c}5,744 \pm 714 \\
(\mathrm{n}=10)\end{array}$ & $\begin{array}{c}29,243 \pm 6,043 \\
(\mathrm{n}=10)\end{array}$ \\
\hline
\end{tabular}

